\title{
Deterioro cognitivo de rápida instauración: neuroborreliosis y proteína 14-3-3 positiva
}

\author{
María Guinda J., Luis Manuel López D., Agustín Martínez Pérez-Balsa, lago Villamil C. y M. Jesús Jove Castelo
}

\begin{abstract}
Gerencia de Atención Primaria Lugo, España. Unidad Docente Burela (MGJ) Hospital da Costa, Burela (Lugo, España)

Servicio de Neurología (LMLD) Servicio Medicina Interna. (IVC, $\mathrm{MJJC})$

Recibido: 11 de enero de 2011
\end{abstract}

Correspondencia a: lago Villamil Cajoto iago.villamil.cajoto@sergas.es

\section{Sr. Editor:}

La enfermedad de Lyme cursa con manifestaciones cutáneas, cardíacas, neurológicas y articulares. Las manifestaciones neurológicas precoces incluyen meningitis linfocitaria, neuropatía craneal (parálisis facial unilateral o bilateral) y radiculoneuritis. Entre las manifestaciones tardías se incluyen encefalomielitis progresiva y polineuropatía periférica ${ }^{1}$.

Presentamos el caso de una paciente, mujer de 78 años previamente autónoma para las tareas básicas de la vida diaria, que desde un mes antes de consultar comenzó con astenia, debilidad generalizada, apatía, inestabilidad de la marcha seguida de somnolencia con desconexión del entorno y dificultad para la ingesta. En la exploración neurológica presentaba desorientación en el tiempo, desinhibición, risa inmotivada, no obedecía órdenes, grasping y reflejo de hociqueo (+) junto con rigidez generalizada. No se evidencian signos de focalidad motora ni sensitiva. Laboratorio: hemograma y pruebas bioquímicas normales. Serología para enfermedad de Lyme (IgG e IgM): (+). Los estudios de sífilis, tiroides, anticuerpos (Ac.) anti-gliadina Ac. anti-tiroglobulina, Vitamina B12, Ac. antinucleares, Ac. anti citoplasma de neutrófilo y los Ac onco-neuronales fueron normales o negativos. Las pruebas de neuroimagen (TAC y RM encefálicas) resultaron normales. En el estudio de LCR se observaron: 150 leucocitos $/ \mathrm{mm}^{3}$ (99\% mononucleares), proteinorraquia: 105,3 mg/dl, glucorraquia normal, ADA 11,6 (valor normal < 10), antígeno de Criptococcus spp, RPC para virus herpes simplex y citología para células malignas negativos; proteína 14-3-3 positiva. El electroencefalograma describió una discreta lentificación del trazado en áreas medias y anteriores del hemisferio izquierdo. Ante los datos de inflamación de LCR iniciales y a la espera de los resultados de las pruebas, se comenzó tratamiento con ampicilina y aciclovir añadiéndose dos días después tuberculostáticos y prednisona. Con ello experimentó una importante mejoría clínica en los tres días siguientes, mostrándose orientada, colaboradora y con exploración neurológica normal. Igualmente se comprobó una mejoría franca de los parámetros infamatorios en el LCR, por lo que se suspendieron los tuberculostáticos. $\mathrm{Al}$ recibir los resultados de la serología para Borrelia sp (serología IgG +) se suspendió el tratamiento previo y se administró ceftriaxona i.v durante dos semanas más. En el momento del alta la paciente se encontraba asintomática, completamente recuperada.

En esta paciente se descartaron, en primer lugar, causas de deterioro cognitivo rápidamente progresivo entre las que se encuentran demencias rápidamente progresivas (enfermedad de Creutzfeldt-Jakob) (ECJ), causas infecciosas, metabólicas, enfermedad tiroidea y encefalopatías autoinmunes ${ }^{2}$. El diagnóstico se basó en un cuadro clínico compatible y serología positiva para Borrelia burgdoferi en ausencia de otra etiología. La prueba de laboratorio más sensible y específica para el diagnóstico de neuroborreliosis es la demostración de la síntesis intratecal de Ac. específicos para B. burgdorferii; también puede ser de utilidad el cultivo de microorganismos y RPC a partir del LCR ${ }^{3}$. La proteina 14-3-3 puede ser positiva en una multitud de procesos (ECJ, esclerosis múltiple fulminante, ictus, encefalitis, etc. $)^{4}$. La neuroborreliosis es una causa infrecuente de dicha positividad. Algunas proteínas del LCR procedentes del cerebro actúan como marcadores de patologías; así, las enolasas específicas de las neuronas son marcadores de muerte neuronal ${ }^{6}$. Se cree que la presencia de proteína 14-3-3 en LCR es también un marcador de muerte neuronal ${ }^{7}$, por lo que puede presentarse como falso positivo en el estudio diagnóstico de un deterioro cognitivo. La determinación de la proteína 14-3-3 en el LCR es una prueba diagnóstica muy sensible (94\%), alta- 
mente específica (93\%) y con valores predictores positivo y negativo elevados (95 y 92\%, respectivamente) para el diagnóstico de la ECJ esporádica ${ }^{7}$. Presenta también falsos positivos (encefalitis de Hashimoto, encefalitis herpética y causada por otros virus, hemorragia subaracnoidea, hipoxia cerebral, encefalopatía metabólica después de intoxicación con barbitúricos, glioblastoma, encefalopatía paraneoplásica, enfermedad cerebrovascular aguda, entre otros, que se reducen considerablemente cuando se realiza la determinación de esta proteína en un contexto clínico de sospecha. Como en nuestro caso, la positividad de esta proteína no debe confundir ante la posibilidad de falso positivo para la enfermedad por priones. En la neuroborreliosis, las alteraciones neurológicas se tratan con ceftriaxona o penicilina por vía iv durante 2-4 semanas, dependiendo de la gravedad. El papel de los corticosteroides no está claro, suele limitarse a pacientes con inflamación importante y que no mejoran con altas dosis de antimicrobianos.

\section{Referencias}

1.- Corral I, Quereda C, Guerrero R, Escudero R, Martí-Belda P. Manifestaciones neurológicas en pacientes con serología positiva frente a Borrelia burgdorferi. Rev Neurología 1997; 12: 2-8.

2.- Geschwind M, Haman A, Miller B. Rapidly progresssive dementia 2007; 25: 783-807.

3.- García-Monco JC, Benach JL. Lyme neuroborreliosis:Ann Neurol 1995; 37: 691-702

4.- Bradley W, Daroff R, Fenichel G, Jankovic Neurología Clínica 2010; 2: 1588-9.

5.- Hansen K, Lebech AM. The clinical and epidemiological profile of Lyme neuroborreliosis in Denmark 1985-1990. Brain 1992; 115: 399-423.

6.- Mokuno K, Kato K, Kawai K. Neuron specific enolase and S-100 protein levels in CSF of patients with various neurological diseases. J Neurol Sci 1983; 60: 443-51.

7.- Zerr I, Bodemer M, Gefeller O, Otto M, Poser S. Detection of 14-3-3 protein in the cerebrospinal fluid supports the diagnosis of Creutzfeldt- Jakob disease. Ann Neurol 1998; 43: 32-40. 